EXTENDED REPORT

\title{
Intraocular and plasma levels of cellular fibronectin in patients with uveitis and diabetes mellitus
}

\author{
K Probst, R Fijnheer, P Schellekens, A Rothova
}

Br J Ophthalmol 2004;88:667-672. doi: 10.1136/bjo.2003.026542

See end of article for authors' affiliations

......................

Correspondence to: K Probst, MD, FC Donders Institute of Ophthalmology, University Hospital Utrecht, PO Box 85 500, 3508 GA Utrecht, Netherlands kprobst@oogh.azu,nl

Accepted for publication 1 October 2003

\begin{abstract}
Aim: To determine intraocular and plasma levels of cellular fibronectin (cFN) in patients with uveitis or diabetes mellitus (DM) and to assess the association with disease activity, macular oedema, and vascular leakage on fluorescein angiography. In addition, to examine whether cFN is locally produced in the eye. Methods: Intraocular and plasma levels of cFN were determined by ELISA in 39 patients with uveitis (23 active, 16 non-active), in 11 patients with DM (eight with and three without diabetic retinopathy) and in 17 control patients. The influence of diabetic retinopathy, inflammatory activity, vascular leakage, and macular oedema $(\mathrm{MO})$ on intraocular and plasma cFN levels was studied. Local production of cFN was determined by calculating absolute and relative intraocular to plasma ratios. Aqueous and vitreous levels of cFN were compared.

Results: No differences in plasma cFN levels were found between patients with uveitis, DM, or controls. Intraocular cFN levels were significantly raised in patients with uveitis and DM, specifically in those with active disease (active uveitis and active diabetic retinopathy versus controls: $p=0.001$ and 0.002 respectively). Further, intraocular cFN levels were significantly elevated in patients with macular oedema or vascular leakage, irrespectively of whether associated with uveitis or DM ( $p=0.001$ and 0.002$)$. Intraocular cFN levels were consistently higher in the vitreous than the aqueous. Intraocular production of cFN was documented by elevated absolute and relative intraocular to plasma ratios in nine out of 11 patients tested.

Conclusions: Elevated intraocular cFN levels were found in uveitis and DM, especially in those with active processes, intraocular vascular damage, and $\mathrm{MO}$. These results suggest that locally produced cFN levels reflect intraocular vascular damage.
\end{abstract}

M acular oedema (MO), an excess of fluid within the retinal tissue, is caused by leakage from retinal or choroidal vessels and represents a final common pathway of various pathological conditions associated with the disruptions of the blood-retinal barrier (BRB) $\cdot{ }^{1-4} \mathrm{MO}$ is a dreaded complication and a major cause of visual loss in uveitis, diabetes mellitus (DM), retinal vascular occlusions, following intraocular surgery, and in other conditions affecting the vasculature of the retina. ${ }^{5-8}$

Vasculitis, with subsequent vascular leakage on fluorescein angiography (FA), is an intraocular inflammatory condition of diverse aetiology, reflecting the activity of the intraocular inflammation. Although commonly idiopathic, it has strong associations with systemic inflammatory diseases. Vascular leakage on FA in patients with DM is caused by pathological vascular wall changes leading to loss of vascular integrity. Vascular leakage and MO are usually investigated with FA, fluorophotometry, or optical coherence tomography (OCT)..$^{9-12}$

Fibronectins (FN) refer to a large family of glycoproteins (440-500 kD), which are major components of the extracellular matrix and play an important part in cell to cell and cell to matrix adhesions. ${ }^{13-15} \mathrm{FN}$ consists as a dimer or a multimer of various similar, but non-identical peptides, resulting in various specific FN variants. The major FN variant found in the bloodstream (soluble or plasma FN) is produced and released by hepatocytes. Endothelial cells, though, can produce a different variant of FN, containing an extra, specific (type III) domain: the cellular or EDl variant. This is only under pathological circumstances, since in normal conditions the produced FN is strictly devoid of the EDl or cellular domain. ${ }^{16-18}$ Besides being produced by endothelial cells, cellular FN ( $\mathrm{CFN}$ ) can also be secreted by a variety of cultured cells including fibroblasts, smooth muscle cells, and possibly also by retinal pigment epithelial (RPE) cells and retinal glia. ${ }^{19-23}$

Elevated plasma levels of circulating $\mathrm{CFN}$ have been described in diverse clinical syndromes with endothelial activation, including systemic vasculitis, and diabetes mellitus, and cFN has been reported as a specific marker for endothelial cell injury. ${ }^{16}{ }^{24-26}$ We hypothesise and show that intraocular levels of cFN reflect intraocular vascular damage and that cFN is locally produced in the eye.

\section{PATIENTS AND METHODS}

The study population consisted of 39 patients with uveitis, 11 patients with DM, and 17 controls (table 1). The group of uveitis patients (mean age 53.8 (SD 20.1) years, range 17.285.9 years) was divided according to the intensity of inflammatory activity, into active $(n=23)$ and non-active uveitis $(n=16)$, depending on whether or not they had reactive cells in the aqueous or vitreous, active vasculitis, papillitis, and/or increasing MO. The group of DM patients (mean age 63.2 (13.3) years, range 38.4-86.2 years) was divided according to the presence of diabetic retinopathy (DRP): DRP positive $(n=8)$ and DRP negative $(n=3)$. The patients were also classified according to various criteria, including the presence of MO and vascular leakage on FA, independent of ocular inflammation or presence of DRP.

Abbreviations: $B R B$, blood-retinal barrier; $\mathrm{CFN}$, cellular fibronectin DM, diabetes mellitus; DRP, diabetic retinopathy; FA, fluorescein angiography; $\mathrm{FN}$, fibronectin; IF, intraocular fluids; $M O$, macular oedema; OCT, optical coherence tomography; PPV, pars plana vitrectomy; RPE, retinal pigment epithelium 


\begin{tabular}{|c|c|c|c|}
\hline & Uveitis & DM & Control \\
\hline Total & 39 & 11 & 17 \\
\hline Male/female ratio & $1: 2.5$ & $1: 0.6$ & 1: 1.1 \\
\hline Mean age at time of sample (years) (SD) & $53.8(20.1)$ & $63.2(13.3)$ & $63.3(15.5)$ \\
\hline Duration of disease (years) (SD) & $3.5(4.3)$ & $3.3(3.1)$ & NA \\
\hline DRP & 0 & $8(73 \%)$ & 0 \\
\hline Active inflammation & $23(59 \%)$ & 0 & 0 \\
\hline MO & $17(47 \%)$ & $6(60 \%)$ & 0 \\
\hline Vascular leakage on FA & $18(67 \%)$ & $7(70 \%)$ & 0 \\
\hline
\end{tabular}

The uveitis group consisted of five patients with anterior uveitis, four intermediate, 13 posterior, 16 panuveitis, and one with sclerouveitis. At the time of sampling, 10/39 uveitis patients were using systemic treatment (corticosteroids and/ or immunosuppressives). Three of 11 DM patients had undergone laser photocoagulation within a 6 month period before sampling.

The control group (mean age 63.3 (15.5) years, range 35.391.5 years) consisted of 17 non-diabetic, non-uveitis patients, with no other ocular diseases than cataract, vitreous floaters, or macular hole.

The research followed the tenets of the Declaration of Helsinki. Informed consent was obtained from all participating patients before collecting ocular and plasma samples.

Blood samples were collected ( $1: 10$ in $3.1 \%$ citrate) from 23 patients and 14 controls, before obtaining the intraocular fluid samples. They were centrifuged immediately and the resulting supernatant plasma samples were stored at $-70^{\circ} \mathrm{C}$.

Intraocular samples consisted of 45 aqueous (30 uveitis, four DM, and 11 controls) and 22 vitreous humour samples (nine uveitis, seven DM, and six controls; table 1). We included one sample (100-200 $\mu \mathrm{l})$ from one eye per patient. Aqueous samples were collected by anterior chamber paracentesis following standard methods. ${ }^{27}$ Aqueous samples from patients with DM and from controls were obtained during cataract surgery. Aqueous tap in uveitis patients was either performed for diagnostic purposes or during cataract surgery. Vitreous samples were collected before a standard three port pars plana vitrectomy (PPV). Before opening the infusion line, undiluted vitreous was aspirated by a vitreous cutter. Samples were obtained from seven DM patients (six underwent PPV because of vitreous haemorrhage and one patient because of a retinal detachment). Nine patients with uveitis underwent PPV for various reasons, which included unestablished diagnosis and retinal pucker. The control group consisted of six patients who underwent vitreoretinal surgery, because of vitreous floaters $(n=3)$, macular holes $(n=2)$, or a retinal pucker $(n=1)$. Intraocular samples were stored immediately at a temperature of $-70^{\circ} \mathrm{C}$.

The intraocular and plasma cFN levels were determined using an ELISA method described earlier, which detects the presence of the extra EDl ("cellular") domain within the whole fibronectin molecule. ${ }^{21}{ }^{26}$ The interassay coefficient of variation measured in 12 microtitre plates was $8.1 \%$, the intra-assay coefficient of variation $4.0 \%$. An amount of $0.4 \mu \mathrm{g} / \mathrm{ml}$ in plasma or ocular fluid could be detected in the linear range of the standard curve.

We compared the cFN levels in plasma and intraocular fluids (IF) between separate groups of patients and controls, and paid special attention to the presence of MO, vascular leakage on FA, and inflammatory activity in uveitis patients or diabetic retinopathy in DM patients. To determine whether the intraocular cFN levels were caused by active local production in the eye or by leakage from the peripheral circulation through pathological vessel walls into the eye, we compared the concentration of cFN in intraocular fluid with the concentration of $\mathrm{cFN}$ in plasma (absolute ratio), but also corrected these for eventual leakage from the peripheral circulation by calculating a relative ratio according to the following equation ${ }^{28}{ }^{29}$ :

(Intraocular cFN concentration)/(Plasma cFN concentration):(Intraocular IgG concentration)/(Plasma IgG concentration)

This was done in 11 patients (four uveitis, seven DM) and nine controls in which plasma and intraocular IgG levels had been determined previously. Values of the corrected, relative IF to plasma ratios above 3.0 were considered indicative of local production. ${ }^{29}$

\section{Statistical analysis}

Data are presented as means (SD). p Values of 0.05 or less were considered significant. Statistical analysis included Kruskall-Wallis and Mann-Whitney U tests for non-parametric analysis (SPSS for Windows 8.0 statistical package, SPSS Inc, Chicago, IL, USA). The small sample sizes in some subgroups should be noted.

\section{RESULTS}

Mean levels of cFN in plasma and intraocular fluids are summarised in tables 2 and 3.

\section{Plasma levels of cFN}

Plasma cFN levels of uveitis, DM, and control samples did not differ $(2.27(1.33) \mu \mathrm{g} / \mathrm{ml}$ and $3.00(1.42) \mu \mathrm{g} / \mathrm{ml}$ versus 2.16 (0.53) respectively; $p=0.85$ and 0.27 ). Subdividing into separate subgroups (uveitis with or without inflammatory activity, MO and vascular leakage; DM with or without DRP, $\mathrm{MO}$, and vascular leakage), no significant differences in the plasma cFN levels were found (compared to controls and to other subgroups).

\section{Intraocular levels of cFN}

In intraocular fluid, cFN levels of uveitis and DM samples were significantly higher than control samples (1.91 (4.00) $\mu \mathrm{g} / \mathrm{ml}$ and 2.58 (3.89) $\mu \mathrm{g} / \mathrm{ml}$ versus $0.34(0.42) \mu \mathrm{g} / \mathrm{ml}$ respectively; $\mathrm{p}=0.011$ and 0.007 (tables 2 and 3). Intraocular cFN levels did not differ between uveitis and DM ( $p=0.29$, table 4). Patients with MO or vascular leakage on FA ( $\mathrm{n}=23$ and 25, respectively) had higher intraocular cFN levels than controls $(p=0.001$ and 0.002$)$, or patients without MO or leakage ( $n=23$ and $12 ; p=0.018$ and 0.019). Again, in these patients with $\mathrm{MO}$ and/or vascular leakage, there were no differences in CFN regarding the aetiology of their disease (uveitis or DM). Intraocular CFN levels were similar for MO negative, vascular leakage negative and control samples. No differences in CFN were found between vitreous samples with or without previous haemorrhage $(p=0.73)$, nor was there 
Table 2 Plasma and intraocular levels of cellular fibronectin in uveitis

\begin{tabular}{|c|c|c|c|c|c|c|c|c|}
\hline & \multirow{2}{*}{$\frac{\text { Plasma }(\mu \mathrm{g} / \mathrm{ml})}{\text { Mean (SD) (n) }}$} & \multirow[b]{2}{*}{ p Value* } & \multirow{2}{*}{$\begin{array}{l}\text { Intraocular fluid } \\
(\mu \mathrm{g} / \mathrm{ml}) \\
\text { Mean (SD) (n) }\end{array}$} & \multirow[b]{2}{*}{ p Value } & \multirow{2}{*}{$\frac{\text { Aqueous }(\mu \mathrm{g} / \mathrm{ml})}{\text { Mean }(\mathrm{SD})(\mathrm{n})}$} & \multirow[b]{2}{*}{ p Value } & \multirow{2}{*}{$\frac{\text { Vitreous }(\mu \mathrm{g} / \mathrm{ml})}{\text { Mean (SD) }(\mathrm{n})}$} & \\
\hline & & & & & & & & \\
\hline $\begin{array}{l}\text { Controls } \\
\text { Uveitis }\end{array}$ & $2.16(0.53)(14)$ & & $0.34(0.42)(17)$ & & $0.18(0.23)(11)$ & & $0.64(0.55)(6)$ & \\
\hline Total & $2.27(1.33)(13)$ & 0.85 & $1.91(4.00)(39)$ & 0.009 & $0.65(0.88)(30)$ & 0.008 & $6.09(6.89)(9)$ & 0.10 \\
\hline Active & 2.28 (1.23) (5) & 0.71 & $2.94(4.97)(23)$ & 0.001 & 0.87 (1.08) (16) & 0.001 & $7.66(7.08)(7)$ & 0.032 \\
\hline Non-active & $2.26(1.47)(8)$ & 1.00 & $0.43(0.51)(16)$ & 0.39 & $0.41(0.52)(14)$ & 0.18 & $0.57(0.54)(2)$ & - \\
\hline $\mathrm{MO}+$ & $1.71(1.00)(7)$ & 0.21 & $3.32(5.70)(17)$ & 0.015 & $0.82(1.27)(12)$ & 0.020 & $9.30(7.87)(5)$ & 0.14 \\
\hline $\mathrm{MO}-$ & $3.13(1.50)(5)$ & 0.20 & 0.78 (1.21) (19) & 0.09 & $0.44(0.43)(3)$ & 0.053 & $2.07(2.25)(4)$ & 0.20 \\
\hline Leakage+ & 1.95 (1.37) (7) & 0.33 & $3.08(5.46)(19)$ & 0.012 & $0.52(0.57)(13)$ & 0.032 & $8.637(7.23)(6)$ & 0.078 \\
\hline Leakage- & $2.98(1.5)(4)$ & 0.29 & $0.79(1.53)(8)$ & 0.60 & 0.88 (1.64) (7) & 0.38 & $0.19(1)$ & - \\
\hline
\end{tabular}

*p Values result from Mann-Whitney tests, compared to control samples.

$\mathrm{MO}=$ macular oedema; leakage = vascular leakage on fluorescein angiography.

any effect of systemic treatment or laser photocoagulation noted $(\mathrm{p}=0.64$ respectively 0.46$)$.

\section{Uveitis}

Subdividing the uveitis group according to the presence of inflammatory activity, the group with active uveitis exhibited elevated cFN levels, which were significantly raised compared to controls and non-active uveitis $(p=0.001$ and 0.003, respectively, table 2). No difference in intraocular cFN levels was found between controls and patients with non-active uveitis. Intraocular cFN levels were significantly raised in uveitis patients with MO (compared to controls, $\mathrm{p}=0.015$ ). Uveitis samples with vascular leakage showed elevated levels of intraocular cFN when compared to controls and uveitis samples without leakage $(p=0.002$ and 0.019 , respectively, tables 2 and 4 ). There were no significant differences between the different forms of uveitis (anterior, intermediate, posterior, or panuveitis) or between the different causes of the uveitis.

\section{Diabetes mellitus}

On dividing the DM group according to the presence of DRP, the DRP positive group showed elevated CFN levels (compared to controls, $\mathrm{p}=0.002$; compared to DRP negative group, $\mathrm{p}=0.025$, tables 3 and 4 ). No difference in intraocular cFN levels was found for DRP negative and control samples $(\mathrm{p}=0.63)$. Subdividing the DM group according to the presence of MO, the MO positive group exhibited significantly elevated cFN levels, compared to controls and to the MO negative group $(p=0.001$ and 0.011 respectively). Samples of DM patients with vascular leakage demonstrated elevated levels of cFN (compared to controls and leakage negative patients; $p=0.002$ and 0.03 ). No differences in intraocular cFN were noted between MO negative DM samples, vascular leakage negative DM samples, and controls. Vitreous samples were obtained from seven DM patients, six of whom with previous vitreous haemorrhage and the remaining patient without. This patient had the lowest cFN levels of these seven vitreous samples $(0.39 \mu \mathrm{g} /$ ml; mean $3.8(4.4) \mu \mathrm{g} / \mathrm{ml}$ ), with a relative ratio of 75.5, highly indicative of local production of cFN.

\section{Intraocular fluid versus plasma}

Intraocular cFN levels in controls were significantly lower than in plasma $(0.34$ versus $2.16 ; \mathrm{p}=0.000)$. In contrast, intraocular levels of cFN in patients with uveitis and DM did not significantly differ from the plasma levels $(p=0.59$ and 0.86 respectively). The mean absolute IF to plasma ratio (uncorrected for leakage from the peripheral circulation) was 0.16 for the controls, whereas it was 0.28 for uveitis and 0.78 for DM (table 5). Intraocular cFN concentrations exceeding plasma cFN concentrations were noted in four patients (three DM, one uveitis). Plasma and intraocular IgG levels, needed for calculating the relative IF to plasma ratio to correct for leakage from peripheral circulation, are given in table 6 . Values of the relative IF to plasma ratio above 3, indicative of local production, were found in 7/7 DM (mean 50.7 (28.2, range: 18.7-83.2) and in 2/4 uveitis samples (4.49 and 5.92 respectively), and in none of the controls. The two uveitis patients with relative IF to plasma ratio above 3 were both active, whereas the two patients with relative ratios below 3 were not.

\section{Aqueous versus vitreous fluid}

In controls, aqueous and vitreous cFN levels did not differ (mean cFN level in aqueous was $0.18(0.23) \mu \mathrm{g} / \mathrm{ml}$ and in

Table 3 Plasma and intraocular levels of cellular fibronectin in DM

\begin{tabular}{|c|c|c|c|c|c|c|c|c|}
\hline & \multirow{2}{*}{$\frac{\text { Plasma }(\mu \mathrm{g} / \mathrm{ml})}{\text { Mean (SD) }(\mathrm{n})}$} & \multirow[b]{2}{*}{ p Value* } & \multirow{2}{*}{$\begin{array}{l}\text { Intraocular fluid } \\
\text { ( } \mu \mathrm{g} / \mathrm{ml}) \\
\text { Mean (SD) (n) }\end{array}$} & \multirow[b]{2}{*}{$p$ Value } & \multirow{2}{*}{$\frac{\text { Aqueous }(\mu \mathrm{g} / \mathrm{ml})}{\text { Mean (SD) (n) }}$} & \multirow[b]{2}{*}{ p Value } & \multirow{2}{*}{$\frac{\text { Vitreous }(\mu \mathrm{g} / \mathrm{ml})}{\text { Mean (SD) }(\mathrm{n})}$} & \multirow[b]{2}{*}{ p Value } \\
\hline & & & & & & & & \\
\hline \multicolumn{9}{|l|}{$\begin{array}{l}\text { Controls } \\
\text { DM }\end{array}$} \\
\hline Total & $3.00(1.42)(10)$ & 0.27 & $2.58(3.89)(11)$ & 0.007 & $0.38(0.38)(4)$ & 0.19 & $3.84(4.48)(7)$ & 0.045 \\
\hline $\mathrm{DRP}+$ & $3.24(1.51)(7)$ & 0.16 & $3.46(4.29)(8)$ & 0.002 & $0.58(0.52)(2)$ & - & $4.42(4.61)(6)$ & 0.016 \\
\hline DRP- & $2.44(1.27)(3)$ & 1.00 & $0.25(0.12)(3)$ & 0.63 & $0.18(0.02)(2)$ & - & 0.39 (1) & - \\
\hline $\mathrm{MO}+$ & $3.08(1.59)(6)$ & 0.32 & $4.42(4.62)(6)$ & 0.001 & $-(0)$ & - & $4.42(4.62)(6)$ & 0.016 \\
\hline $\mathrm{MO}-$ & $2.88(1.35)(4)$ & 0.46 & $0.24(0.10)(4)$ & 0.65 & $0.19(0.02)(3)$ & 0.48 & 0.39 (1) & - \\
\hline Leakage+ & 3.24 (1.51) (7) & 0.16 & $3.82(4.50)(7)$ & 0.002 & $0.211(1)$ & - & $4.42(4.61)(6)$ & 0.016 \\
\hline Leakage-- & $2.44(1.27)(3)$ & 1.00 & $0.25(0.12)(3)$ & 0.63 & $0.18(0.02)(2)$ & - & 0.39 (1) & - \\
\hline
\end{tabular}

* $p$ Values result from Mann-Whitney tests, compared to control samples.

$\mathrm{DM}=$ diabetes mellitus; $\mathrm{DRP}=$ diabetic retinopathy; $M O=$ macular oedema; leakage = vascular leakage on fluorescein angiography. 
Table 4 Results of Mann-Whitney tests ( $p$ values) for levels of cellular fibronectin within and between groups*

\begin{tabular}{|c|c|c|c|c|c|c|c|}
\hline & & & & Plasma & IF & Aqueous & Vitreous \\
\hline Uveitis & $\begin{array}{l}\text { Active } \\
\mathrm{MO}+ \\
\text { Leakage+ }\end{array}$ & $\begin{array}{l}v \\
v \\
v\end{array}$ & $\begin{array}{l}\text { Non-active } \\
\mathrm{MO}- \\
\text { Leakage- }\end{array}$ & $\begin{array}{l}0.77 \\
0.17 \\
0.26\end{array}$ & $\begin{array}{l}0.003 \\
0.25 \\
0.08\end{array}$ & $\begin{array}{l}0.027 \\
0.53 \\
0.45\end{array}$ & $\begin{array}{l}0.08 \\
0.33 \\
-\end{array}$ \\
\hline $\begin{array}{l}\mathrm{MO}+ \\
\mathrm{MO}-\end{array}$ & $\begin{array}{l}\mathrm{DRP}+ \\
\mathrm{MO}+ \\
\text { Leakage+ } \\
\text { Uveitis } \\
\text { Uveitis }\end{array}$ & $\begin{array}{l}v \\
v \\
v \\
v \\
v\end{array}$ & $\begin{array}{l}\text { DRP- } \\
\text { MO- } \\
\text { Leakage- } \\
\text { DM } \\
\text { DM }\end{array}$ & $\begin{array}{l}0.31 \\
0.83 \\
0.31 \\
0.06 \\
0.81\end{array}$ & $\begin{array}{l}0.025 \\
0.011 \\
0.030 \\
0.11 \\
0.33\end{array}$ & $\begin{array}{l}0.12 \\
- \\
- \\
- \\
0.31\end{array}$ & $\begin{array}{l}- \\
- \\
- \\
0.47 \\
-\end{array}$ \\
\hline $\begin{array}{l}\text { Leakage+ } \\
\text { Leakage- }\end{array}$ & $\begin{array}{l}\text { Uveitis } \\
\text { Uveitis }\end{array}$ & $\begin{array}{l}v \\
v\end{array}$ & $\begin{array}{l}\text { DM } \\
\text { DM }\end{array}$ & $\begin{array}{l}0.09 \\
0.72\end{array}$ & $\begin{array}{l}0.21 \\
0.84\end{array}$ & $\overline{0}-77$ & $\begin{array}{l}0.42 \\
-\end{array}$ \\
\hline Total (uveitis+DM) & $\begin{array}{l}\mathrm{MO}+ \\
\text { Leakage+ }\end{array}$ & $\begin{array}{l}v \\
v\end{array}$ & $\begin{array}{l}\text { MO- } \\
\text { Leakage- }\end{array}$ & $\begin{array}{l}0.30 \\
0.82\end{array}$ & $\begin{array}{l}0.018 \\
0.014\end{array}$ & $\begin{array}{l}0.40 \\
0.31\end{array}$ & $\begin{array}{l}0.13 \\
0.028\end{array}$ \\
\hline
\end{tabular}

vitreous $0.64(0.55) \mu \mathrm{g} / \mathrm{ml} ; \mathrm{p}=0.15)$. However, in patients with uveitis or DM, cFN levels were higher in vitreous than in aqueous $(p=0.004$ and 0.023$)$, as well as in patients with active, MO positive and vascular leakage positive uveitis $(\mathrm{p}=0.004,0.015$ and 0.003 , respectively). Though lower than in the vitreous, elevated cFN levels in the aqueous were found in samples of patients with uveitis, specifically in active, MO positive and leakage positive uveitis patients (compared to controls, $\mathrm{p}=0.001,0.02$ and 0.032, table 2). Compared to controls, vitreous cFN levels were significantly raised in the following groups of patients: uveitis, especially in active and leakage or MO positive uveitis and in DM, in those with DRP, MO, and vascular leakage (tables 2 and 3). Patients without $\mathrm{MO}$ and/or vascular leakage were not different from controls $(p=0.36$ and 0.50$)$.

\section{DISCUSSION}

We identified elevated intraocular levels of cFN in patients with uveitis and DM, specifically in patients with active processes, involving intraocular vascular damage and MO. In addition, we observed that cFN was actively produced in the eye itself. In contrast with intraocular cFN, plasma cFN levels were not significantly associated with (active) intraocular vascular disorders.

Elevated plasma levels of cFN have been documented in disorders in which systemic vascular damage from diverse causes was present. ${ }^{24-26}$ Healthy endothelial cells produce virtually no fibronectin containing the extracellular domain ( $\mathrm{CFN})$, but damaged or activated endothelial cells increasingly produce and release cFN into the circulation. Therefore, the use of plasma cFN levels as a marker for endothelial activation in the human body has been proposed. An association with disease severity was noted for DM and pre-eclampsia. ${ }^{25}{ }^{26}$ But since predominantly local processes play a crucial part in active intraocular disease, one could expect that locally produced intraocular levels of cFN are too low to have any effect on systemic plasma cFN levels.

Earlier studies of normal and diseased human ocular structures showed the presence of total FN (cellular and soluble), in very small amounts, in and around the vessels of the ciliary body, the iris, and the retina; at the pigment epithelium of the ciliary body and retina, at the inner limiting membrane, and inhomogeneously distributed throughout the vitreous. ${ }^{30-33}$ A study of iridectomy samples of patients with uveitis exhibited an increased presence of total FN. ${ }^{32}$ In experimental autoimmune uveoretinitis in rats, total FN levels were monitored during different stages of inflammation and documented the increasing presence of total FN in retinal vessels from 2 days before the clinical onset of uveitis. Return to the baseline levels was observed after 5-7 weeks, when the retinal inflammation had subsided..$^{34}$ Other studies on total FN have been performed in diabetic eyes, glaucoma, corneal diseases, retinal detachments, and proliferative vitreoretinopathy (PVR). ${ }^{30} 31$ 35-39

Recently, specific attention was paid to the presence and role of cellular FN in ocular processes. It was suggested that $\mathrm{cFN}$ is involved in the pathogenesis of epiretinal membrane formations. ${ }^{21}$ A study using human cFN antibodies has shown a diffuse distribution of $\mathrm{CFN}$ within membranes extracted from patients with PVR and proliferative DRP, and a localised distribution in neovascular vessels in proliferative DRP membranes. ${ }^{20}{ }^{40}$ However, elevated cFN levels in the vitreous of our DM patients without membranes strongly suggest local production of cFN irrespectively of membrane formation.

Our observation of increased intraocular cFN levels in uveitis and DM could only be explained by an active local intraocular production. In all our patients tested, IF to plasma ratios indicated that the intraocular levels of cFN were higher than can be explained by sole leakage from plasma to IF. As

\begin{tabular}{|c|c|c|c|}
\hline & Control & Uveitis & DM \\
\hline $\begin{array}{l}\text { Absolute IF/plasma ratio }>1 \\
\text { Absolute aqueous/plasma ratio }>1 \\
\text { Absolute vitreous/plasma ratio }>1 \\
\text { Relative IF/plasma ratio }>3\end{array}$ & $\begin{array}{l}0 / 14(0 \%) \\
0 / 9(0 \%) \\
0 / 5(0 \%) \\
0 / 5(0 \%)^{*}\end{array}$ & $\begin{array}{l}1 / 13(8 \%) \\
0 / 12(0 \%) \\
1 / 1(100 \%) \\
2 / 4(50 \%)\end{array}$ & $\begin{array}{l}3 / 10(33 \%) \\
0 / 3(0 \%) \\
3 / 7(43 \%) \\
7 / 7(100 \%)\end{array}$ \\
\hline \multicolumn{4}{|c|}{$\begin{array}{l}\text { IF = intraocular fluid; DM = diabetes mellitus. } \\
\text { *Four out of } 9 \text { control samples were left out of the analysis, because they had no detectable intraocular lgG, whic } \\
\text { would otherwise have caused falsely elevated relative ratios. }\end{array}$} \\
\hline
\end{tabular}


Table 6 Plasma and intraocular levels of $\lg G^{*}$

\begin{tabular}{llll}
\hline & No & Plasma (g/l) & Intraocular fluid (g/l) \\
\hline Controls & 9 & $14.1(5.0)$ & $0.04(0.08)$ \\
Uveitis & 4 & $14.2(3.2)$ & $0.9(1.2)$ \\
DM & 7 & $15.0(3.2)$ & $0.4(0.3)$ \\
\hline
\end{tabular}

*Values are means (SD). DM = diabetes mellitus.

we measured the whole cFN structure and not only the EDI domain (fragment), it is not probable that this large glycoprotein would leak through the BRB, considering the molecular weight of $\mathrm{cFN}(500 \mathrm{kD}) .{ }^{41}$ Moreover, in four patients the absolute amount of intraocular cFN was found higher than the amount of cFN in their plasma.

The origin of the intraocular cFN is not clear. In various systemic disorders, the evidence of predominant local production of FN by vascular endothelial cells was noted. ${ }^{17} 4243$ The production of cFN in eyes can therefore be ascribed to damaged endothelium of retinal and/or iris vessels. In vitreoretinal membranes, the production of cFN was, next to the endothelium of neovessels, also ascribed to (migrated) RPE cells. ${ }^{21} 4445$ It was proved that RPE cells can synthesise FN, but the distinction between which FN types (cellular or soluble) has not yet been performed. TGF- $\beta$ has been reported to be a potent stimulator of FN release by RPE cells, ${ }^{44}$ and human serum (as a model of vascular leakage in vivo) has been reported to contain substances stimulating FN synthesis in cultured human RPE cells. Retinal glia and/or fibroblast-like cells in vitreoretinal membranes have also been shown to contain FN mRNA, but their contribution to the cFN production is still uncertain. ${ }^{23}$

As we found elevated cFN levels in samples without membranes and haemorrhaging, and evidence of local production, we consider the vascular endothelium to be the main site of production of cFN, but additional production by RPE, glial, or fibroblast-like cells cannot be excluded. Since cFN is partly matrix bound, actual on-site levels of intraocular cFN synthesis might even be higher than we measured in the vitreous and aqueous.

We have consistently found higher levels of cFN in the vitreous than in the aqueous. However, the majority of patients had posterior segment disease so that the main site of cFN production and release was located in the posterior segment. High aqueous cFN levels would then be expected in anterior segment disease, which is consistent with our findings. The additional effect of pooling of $\mathrm{cFN}$ in the gelatinous vitreous cannot be excluded. The simultaneous measurements of cFN in the aqueous and vitreous would be needed to elucidate these differences.

In patients with $\mathrm{MO}$ and/or vascular leakage on FA, the levels of cFN were similar for patients with uveitis and DM. One might hypothesise that, although the initial cause of vascular damage is different, the subsequent mechanisms following vascular destruction might be quite similar. The clinically observed ischaemia, vascular leakage, and MO may therefore represent a final common pathway of events from various causes.

Because of the nature of this study and the difficulty to obtain human intraocular samples, we were unfortunately not able to collect larger groups of samples, which could have improved our statistical power (especially in our subgroup analysis). Future studies of larger groups of patients and controls are needed, to asses the relation between the extent of vascular changes and the levels of intraocular $\mathrm{CFN}$ and to unravel the exact mechanism and location of intraocular cFN production.

Although our findings provide us with new insights about the pathogenesis of MO and vascular involvement, the clinical application/use of cFN as a marker of endothelial cell damage or to monitor disease activity is probably limited in practice, since it needs intraocular sampling.

In conclusion, we showed local production of cFN in eyes affected by intraocular vascular damage. High levels of cFN were specifically exhibited in patients with active retinal vascular disease and MO, regardless of their origin. These findings enhance our understanding of the pathogenic mechanisms of ocular vascular disorders.

\section{Authors' affiliations}

K Probst, P Schellekens, A Rothova, FC Donders Institute of Ophthalmology, University Medical Center, Utrecht, Netherlands R Fijnheer, Department of Haematology, University Medical Center, Utrecht, Netherlands

This study was supported in part by the Dr FP Fischer Foundation, Utrecht, Netherlands.

\section{REFERENCES}

1 Marmor MF. Mechanisms of fluid accumulation in retinal edema. Doc Ophthalmol 1999;97:239-49.

2 Tessler H, Lam S. Cystoid macular edema. In: Pepose JS, Holland GN, Wilhelmus KR, eds. Ocular infection and immunity. St Louis: Mosby: 553-9.

3 Bresnick GH. Diabetic maculopathy. A critical review highlighting diffuse macular edema. Ophthalmology 1983;90:1301-17.

4 Vinores S, Amin A, Derevjanik NL, et al. Immunohistochemical localization of blood-retinal barrier breakdown sites associated with post-surgical macular oedema. Histochem J 1994;26:655-65.

5 Klein R, Klein BEK, Moss SE, et al. The Wisconsin epidemiologic study of diabetic retinopathy. IV Diabetic macular edema. Ophthalmology 1984;91:1464-74.

6 Bresnick GH. Diabetic macular edema. A review. Ophthalmology 1986;93:989-97.

7 Guex-Crosier Y. The pathogenesis and clinical presentation of macular edema in inflammatory diseases. Doc Ophthalmol 1999;97:297-309.

8 Rothova A, Suttorp-van Schulten MSA, Treffers WF, et al. Causes and frequency of blindness in patients with intraocular inflammatory disease. Br J Ophthalmol 1996;80:332-6.

9 Varano M, Scassa C, Ripandelli G, et al. New diagnostic tools for macular edema. Doc Ophthalmol 1999;97:373-9.

10 Smith RT, Lee CM, Charles HC, et al. Quantification of diabetic macular edema. Arch Ophthalmol 1987;105:218-22.

11 Nussenblatt RB, Kaufman SC, Palestine AG, et al. Macular thickening and visual acuity. Measurement in patients with cystoid macular edema. Ophthalmology 1987;94:1134-9.

12 Hee MR, Puliafito CA, Wong C, et al. Quantitative assessment of macular edema with optical coherence tomography. Arch Ophthalmol 1995; 113:1019-29.

13 Hynes RO. Fibronectins. Sci Am 1986;254:42-51.

14 Hynes RO. Molecular biology of fibronectin. Annu Rev Cell Biol 1985; 1:67-90.

15 Ruoslahti E. Fibronectin and its receptors. Annu Rev Biochem 1988;57:375-413.

16 Magnusson MK, Mosher DF. Fibronectin. Structure, assembly and cardiovascular implications. Arterioscler Tromb Vasc Biol 1998; 18:1363-70.

17 Peters JH, Ginsberg MH, Bohl BP, et al. Intravascular release of intact cellular fibronectin during oxidant-induced injury of the in vitro perfused rabbit lung. J Clin Invest 1986;78:1596-603.

18 Peters JH, Ginsberg MH, Case Cm, et al. Release of soluble fibronectine containing an extra type III domain (EDI) during acute pulmonary injury mediated by oxidants or leukocytes in vivo. Am Rev Resp Dis 1988; 138:167-74

19 Clark R, Quinn J, Winn H, et al. Fibronectin is produced by blood vessels in response to injury. J Exp Med 1982;156:646-51.

20 Hiscott $\mathbf{P}$, Waller HA, Grierson I, et al. The extracellular matrix of reparative tissue in the vitreous: fibronectin production in proliferative diabetic retinopathy membranes. Eye 1993;7:288-92.

21 Oshato M, Shiga S, Hitoshi K, et al. Immunohistochemical study of cellular fibronectin in preretinal membranes. Retina 1994;14:430-4.

22 Campochiaro $\mathbf{P}$, Jerdan J, Glaser B. The extracellular matrix of human retinal pigment epithelial cells in vivo and its synthesis in vitro. Invest Ophthalmol Vis Sci 1986;27:1615-21.

23 Hiscott P, Waller HA, Grierson I, et al. Local production of fibronectin by ectopic human retinal cells. Cell Tissue Res 1992;267:185-92.

24 Peters JH, Maunder RJ, Woolf AD, et al. Elevated plasma levels of ED1+ ("cellular") fibronectin in patients with vascular injury. J Lab Clin Med 1989;113:586-97.

25 Lockwood CJ, Peters JH. Increased plasma levels of ED1+ cellular fibronectin precede the clinical signs of preeclampsia. Am J Obstet Gynecol 1990;162:358-62.

26 Kanters SDJM, Banga JD, Algra A, et al. Plasma levels of cellular fibronectin in diabetes. Diabetes Care 2001;24:323-7. 
27 Lelii van $\operatorname{der}$ A, Rothova A. Diagnostic anterior chamber paracentesis in uveitis: a safe procedure? Br J Ophthalmol 1997;81:976-9.

28 Murray P, Hoekzema R, Luyendijk L, et al. Analysis of aqueous humor immunoglobulin $G$ in uveitis by enzyme-linked immunosorbent assay, isoelectric focusing, and immunoblotting. Invest Ophthalmol Vis Sci 1990;31:2129-35.

29 Boer de J, Verhagen C, Bruinenberg M, et al. Serologic and polymerase chain reaction analysis of intraocular fluids in the diagnosis of infectious uveitis. Am J Ophthalmol 1996;121:650-8.

30 Ljubimov AV, Burgeson RE, Butkowski RJ, et al. Basement membrane abnormalities in human eyes with diabetic retinopathy. $J$ Histochem Cytochem 1996:44:1469-79.

31 Roy S, Cagliero E, Lorenzi M. Fibronectin overexpression in retinal microvessels of patients with diabetes. Invest Ophthalmol Vis Sci 1996;37:258-66

32 Ni M, Chan CC, Nussenblatt RB, et al. Iris inflammatory cells, fibronectin fibrinogen, and immunoglobulin in various ocular diseases. Arch Ophthalmol 1988; 106:392-5

33 Fujikawa LS, Chan CC, McAllister C, et al. Retinal vascular endothelium expresses fibronectin and class II histocompatibility complex antigens in experimental autoimmune uveitis. Cell Immunol 1987; 106:139-50.

34 Wang J, Lin WL, Essner E, et al. Ultrastructural and immunocytochemical studies of iris vessels in rats with experimental autoimmune uveoretinitis. Curr Eye Res 1994; 13:747-54.

35 Dunker S, Kleinert R, Faulborn J. Immunhistologische Untersuchungen des Glasskörpers. Ophthalmologe 1998;95:8-12.
36 Vesaluoma M, Mertaniemi P, Mannonen S, et al. Cellular and plasma fibronectin in the aqueous humour of primary open-angle glaucoma, exfoliate glaucoma and cataract patients. Eye 1998;12:886-90

37 Barlati S, Marchina E, Quaranta CA, et al. Analysis of fibronectin, plasminogen activators and plasminogen in tear fluid as markers of corneal damage and repair. Exp Eye Res 1990;51:1-9.

38 Kenarova B, Voinov L, Apostolov C, et al. Levels of some cytokines in subretinal fluid in proliferative vitreoretinopathy and rhegmatogenous retinal detachment. Eur J Ophthalmol 1997;7:64-7.

39 Casaroli Marano RP, Vilaro S. The role of fibronectin, laminin, vitronectin and their receptors on cellular adhesion in proliferative vitreoretinopathy. Invest Ophthalmol Vis Sci 1994;35:2791-803.

40 Grisanti S, Heimann, Wiedemann P. Origin of fibronectin in epiretinal membranes of proliferative vitreoretinopathy and proliferative diabetic retinopathy. Br J Ophthalmol 1993;77:238-42.

41 Kornblihtt A, Pesce C, Alonso C, et al. The fibronectin gene as a model for splicing and transcription studies. FASEB J 1996;10:248-57.

42 Sobel R, Mitchell M. Fibronectin in multiple sclerosis lesions. Am J Pathol 1989:135:161-8.

43 Clark R, Dvorak H, Colvin R. Fibronectin in delayed-type hypersensitivity skin reactions: associations with vessel permeability and endothelial cell activation. J Immunol 1981;126:787-93.

44 Kamei M, Kawasaki A, Tano Y. Analysis of extracellular matrix synthesis during wound healing of retinal pigment epithelial cells. Microsc Res Tech 1998:42:311-16.

45 Stocks SZ, Shiels IA, Taylor SM. Homologous serum-stimulated fibronectin synthesis in human retinal pigmented epithelial cells. Aust NZ J Ophthalmol 1999;27:247-9. 